\title{
Protective role of selenium on thyroid morphology in iodine-induced autoimmune thyroiditis in Wistar rats
}

\author{
IOANA VASILIU $^{1 *}$, DELIA-GABRIELA CIOBANU-APOSTOL ${ }^{2,3^{*}}$, IOANA ARMASU $^{1}$, \\ OVIDIU BREDETEAN ${ }^{4}$, IONELA LACRAMIOARA SERBAN ${ }^{1}$ and CRISTINA PREDA ${ }^{5,6}$
}

\begin{abstract}
Departments of ${ }^{1}$ Physiology and ${ }^{2}$ Morphopathology, 'Grigore T. Popa' University of Medicine and Pharmacy, 700115 Iasi; 'Prof. Dr. Gioconda Dobrescu' Department of Pathology, 'Sf. Spiridon' County Hospital, 700111 Iasi; Departments of ${ }^{4}$ Pharmacology and ${ }^{5}$ Endocrinology, 'Grigore T. Popa' University of Medicine and Pharmacy, 700115 Iasi; ${ }^{6}$ Department of Endocrinology, 'Sf. Spiridon' County Hospital, 700111 Iasi, Romania
\end{abstract}

Received May 18, 2020; Accepted June 17, 2020

DOI: $10.3892 /$ etm.2020.9029

\begin{abstract}
Excess iodine may induce and exacerbate autoimmune thyroiditis (AIT) in humans and animals. In order to assess the potential protective mechanisms of selenium (Se) in thyroid autoimmunity, the effects of inorganic Se (sodium selenite) administration on thyroid morphology and follicular cytology were investigated in adult Wistar rats with iodine-induced AIT. A total of 48 adult Wistar rats (24 females, 24 males) were allocated to one of four dietary regimens: $\mathrm{C} 0$, control; $\mathrm{C} 1$, only potassium iodine (KI); C2, concomitant $\mathrm{KI}$ and Se; C3, only KI initially, followed by Se administration. For AIT induction the rats were fed with $0.05 \%$ KI for 56 days. Se-treated rats received $0.3 \mathrm{mg} / \mathrm{l}$ sodium selenite in drinking water. Thyroid tissues were collected for pathologic diagnosis after 7 days in $\mathrm{C} 0$ group, 56 days in $\mathrm{C} 1$ and $\mathrm{C} 2$ groups, and 112 days in $\mathrm{C} 3$ group. In $\mathrm{C} 1$ group, moderate to severe thyroiditis was observed in $83 \%$ of males and $50 \%$ of female rats $(\mathrm{P}=0.223)$. In $\mathrm{C} 3$ group $16.7 \%$ of male rats developed moderate thyroiditis and none in $\mathrm{C} 2$ group, whereas no females were identified with moderate to severe thyroiditis in $\mathrm{C} 2$ or $\mathrm{C} 3$ group. Thus, the administration of Se was proven to have protective effects against thyroiditis cytology in both male and female Wistar rats.
\end{abstract}

\section{Introduction}

As most human autoimmune disorders, autoimmune thyroiditis (AIT) (chronic lymphocytic thyroiditis/Hashimoto's

Correspondence to: Dr Ioana Armasu, Department of Physiology, 'Grigore T. Popa' University of Medicine and Pharmacy, 16 Universitatii Street, 700115 Iasi, Romania

E-mail: ioana.armasu@umfiasi.ro

*Contributed equally

Key words: selenium, experimental autoimmune thyroiditis, iodine-induced thyroiditis in Wistar rats, iodine-induced thyroid dysfunction, selenium effect on thyroid pathology thyroiditis) results from a combination of genetic predisposition and environmental triggers (1). Clinical and epidemiologic evidence point to excessive iodine intake as the environmental agent responsible for the thyroid autoimmunity induction $(2,3)$. The role of iodine in the homeostatic regulation of thyroid function was first demonstrated $>50$ years ago. However, the precise mechanism of regulation remains unclear (4). High doses of iodide suppress the functional activity of the thyrocytes (Wolff-Chaikoff effect), inhibiting the iodination of the thyroid protein fraction and decreasing the concentration of thyroid hormones in serum (5). It has been demonstrated that a single injection of a high dose of iodide inhibits the biosynthesis of thyroid hormones at several levels $(6,7)$. The sensitivity to the stimulating action of thyroid-stimulating hormones decreases and the expression and activity of thyroperoxidase (the enzyme catalyzing iodination of thyroglobulin in the presence of iodide and hydrogen peroxide) are suppressed (8). Finally, the NADPH-oxidase reaction producing $\mathrm{H}_{2} \mathrm{O}_{2}$ (the limiting step in the iodide metabolism) is also suppressed $(7,9)$. The necrotic effect is increased in case of selenium (Se) deficiency $(10,11)$. However, thyroid cells have their own antioxidant system. Thus, in the case of iodine excess, the expression of antioxidative enzymes increases (12). Therefore, the first iodine-induced thyroiditis has been transient in most experimental animals, except for genetically modified animals prone to develop AIT, such as non-obese diabetic (NOD) mice. They present important areas of destroyed thyroid tissue which are replaced by inflammatory tissue (13).

Experimental autoimmune thyroiditis (EAT) has been used to simulate human autoimmune thyroid disease for decades (14). EAT can be easily induced in genetically susceptible strains of mice by excess iodine ingestion (15) or by immunization with mouse thyroglobulin (16).

However, iodine excess alone has also been used to induce EAT in insusceptible murine models, including Wistar rats $(17,18)$, as well as in other animals (19). Iodine excess is a cheap and efficient method for EAT induction.

The aim of the present study was to assess the effects of inorganic Se supplementation on thyroid morphology in EAT induced by the administration of potassium iodide $(\mathrm{KI})$ in Wistar rats. 
Table I. Study group allocation and treatment regimens.

\begin{tabular}{lcccc}
\hline Factors & C0 & C1 & C2 & C3 \\
\hline Sex (males/females) & $6 / 6$ & $6 / 6$ & $6 / 6$ & $6 / 6$ \\
KI administration & No & 56 days of KI & 56 days of KI & 56 days of KI \\
Na-Se administration & No & No & $\begin{array}{c}56 \text { days of Na-Se, } \\
\text { concomitant with }\end{array}$ & $\begin{array}{c}56 \text { days of Na-Se, } \\
\text { after the KI } \\
\text { administration } \\
\text { Total days of treatment/observation }\end{array}$ \\
\hline
\end{tabular}

$\mathrm{KI}$, potassium iodine; Na-Se, sodium selenite.

\section{Materials and methods}

Animals. A total of 48 Wistar adult rats (24 females weighing $160 \pm 20 \mathrm{~g}$ and 24 males weighing $180 \pm 20 \mathrm{~g}$ ) were used for the present study. The animals were obtained from the 'Victor Babes' National Institute of Research Development in the Pathology Domain and Biomedical Sciences (Bucharest, Romania). Wistar rats were housed under standard conditions at the Biobase for research animals of 'Grigore T. Popa' University of Medicine and Pharmacy (Iasi, Romania) and were fed with standard food. The rats were housed in clean and ventilated polyurethane cages; 2 rats were placed in each cage. All rats were maintained under standard conditions of temperature $\left(20 \pm 40^{\circ} \mathrm{C}\right)$, relative humidity of $55 \pm 10 \%$, and light/dark cycles of 12/12 h consecutively. Access to food and water was ad libidum. The acclimatization of the rats lasted 7 days prior to the study initiation. The study was approved by the Ethics Committee of 'Grigore T. Popa' University of Medicine and Pharmacy.

EAT and Se administration. As AIT is more common in females (3:1) (20-22), it was investigated whether the same susceptibility of the female sex also occurs in the animal model of Wistar rats. The animals were randomized into groups according to four treatment regimens: $\mathrm{C} 0$, two control groups for each sex; $\mathrm{C} 1$, two (male and female) groups that received $\mathrm{KI}$ for 56 days $(0.2 \mathrm{mg}$ per animal in drinking water); $\mathrm{C} 2$, two (male and female) groups that received concomitant $\mathrm{KI}$ and sodium selenite $(0.5 \mathrm{mg} / \mathrm{kg}$ body weight of sodium selenite administered in drinking water) for 56 days; and $\mathrm{C} 3$, two (male and female) groups that received KI for 56 days and afterwards sodium selenite for another 56 days (Table I).

Even though no dose-finding study was performed, a previous report (23) concerning sodium selenite administration in Wistar rats has shown consistent toxic effects of sodium selenite at a dose of $>1 \mathrm{mg} / \mathrm{kg}$ body weight (using the same administration method: ad libitum in drinking water) $(23,24)$.

Tissue collection and analysis. General anesthesia was performed with a combination of ketamine $(60 \mathrm{mg} / \mathrm{kg}$ body weight) and xylazine ( $8 \mathrm{mg} / \mathrm{kg}$ body weight) administered intraperitoneally. Thyroid tissues were collected for pathology analysis, in accordance with the Council Directive 63/2010/EU on the protection of animals used for scientific purposes, after 7 days in control groups, 56 days in $\mathrm{C} 1$ and $\mathrm{C} 2$ groups, and
112 days in C3 groups. Tissue samples were harvested from the neck area containing the anterior muscular plan, the thyroid and parathyroid tissue and the tracheal tissue with the cartilage ring. In order to keep the thyroid intact, tissue samples were fixed in $10 \%$ formaldehyde at $24^{\circ} \mathrm{C}$ for $24 \mathrm{~h}$. The tissue samples were embedded in paraffin and cut into $4-\mu \mathrm{m}$ thick sections. Next, the tissue samples were stained with hematoxylin and eosin (H\&E) for $40 \mathrm{~min}$, or van Gieson's (VG) stain for $15 \mathrm{~min}$ at room temperature $22-24^{\circ} \mathrm{C}$. The morphometric evaluation was performed using a light microscope, with x10 objective. For positive and negative control, thyroid and parathyroid tissues were immunohistochemically stained with synaptophysin, chromogranin, thyroglobulin and thyroid transcription factor (TTF1) at the 'Prof. Dr. Gioconda Dobrescu' Department of Pathology, 'Sf. Spiridon' County Hospital (Iasi, Romania). Parathyroid tissues showed diffuse negative immunoreactivity for chromogranin, synaptophysin and TTF1; parafollicular $\mathrm{C}$ cells were positive for chromogranin and synaptophysin, and thyroid tissue presented diffuse nuclear immunoreactivity for TTF1 and positive cytoplasmic immunoreactivity for thyroglobulin. Immunohistochemistry was performed at room temperature between $22-24^{\circ} \mathrm{C}$. The overnight staining technique was carried out at $4^{\circ} \mathrm{C}$ with a maximum staining duration of $24 \mathrm{~h}$.

The sections were examined and photographed using Nikon Eclipse E600 (Nikon Corporation) and the Lucia Net program, equipped with the Nikon Digital Net Camera DN100 image capture system (Nikon Corporation) and morphometric analysis software (morphometric software LUCIA Net v.16.2 $2^{\circledR}$; Laboratory Imaging s.r.o., with NIS Elements 3.0 ${ }^{\circledR}$ ) at the 'Prof. Dr. Gioconda Dobrescu' Department of Pathology. The morphometric analysis of the thyroid tissues was made from 5 successive images captured from each lobe (digital pictures of 10 non-adjacent $10 x$ fields). The interpretation of histopathological sections and the acquisition of images for all studied animals were performed by a single examiner (DGCA).

Morphopathology parameter assessment. The mean size of thyroid follicles was assessed by measuring the maximum diameter of $\geq 20$ thyroid follicles per case in various areas of the thyroid gland. The mean size of the thyroid follicular epithelium was assessed by measuring the size of the follicular epithelium in fixed positions (at 12, 5 and 7 o'clock) in 20 follicles per case.

The morphological evaluation of thyroid follicles was performed in 20 thyroid follicles for each case and included 


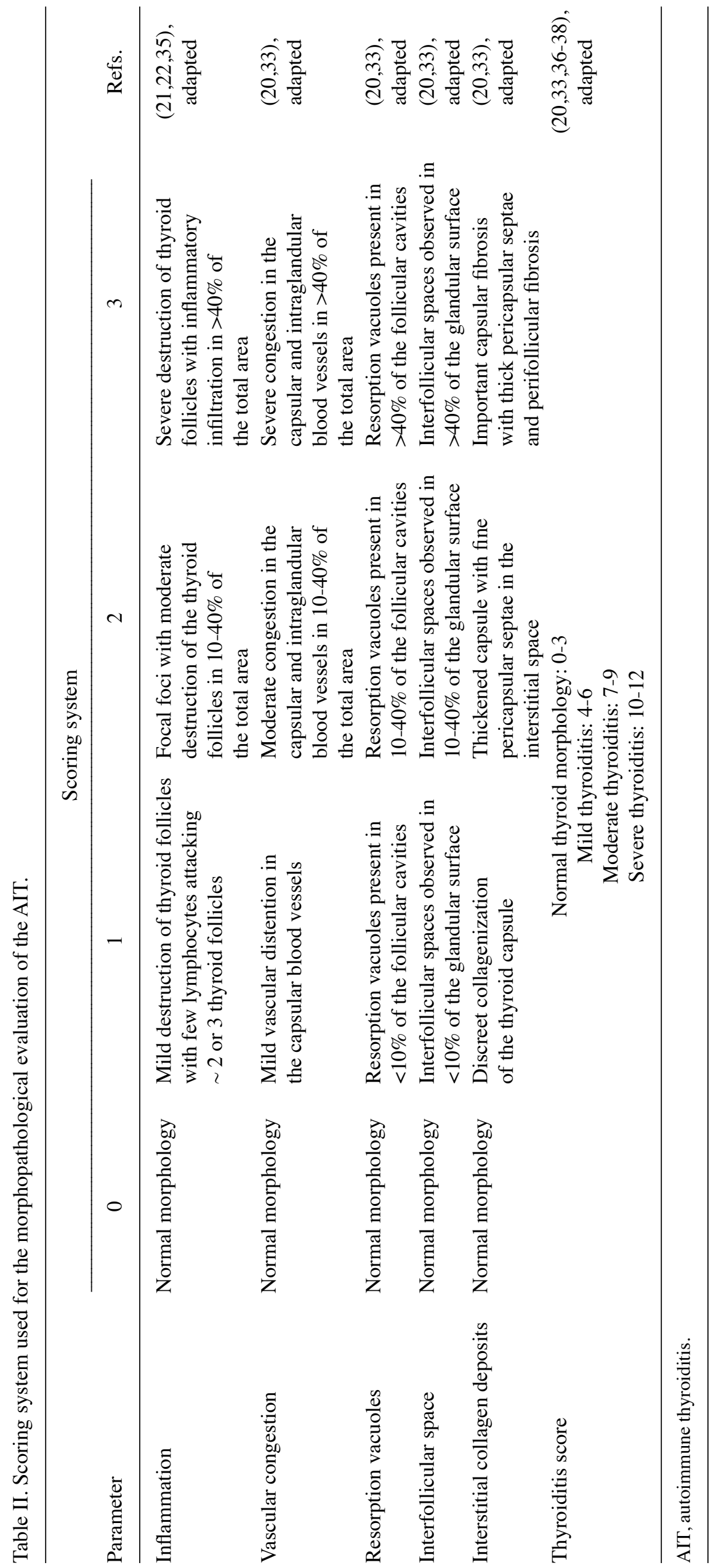




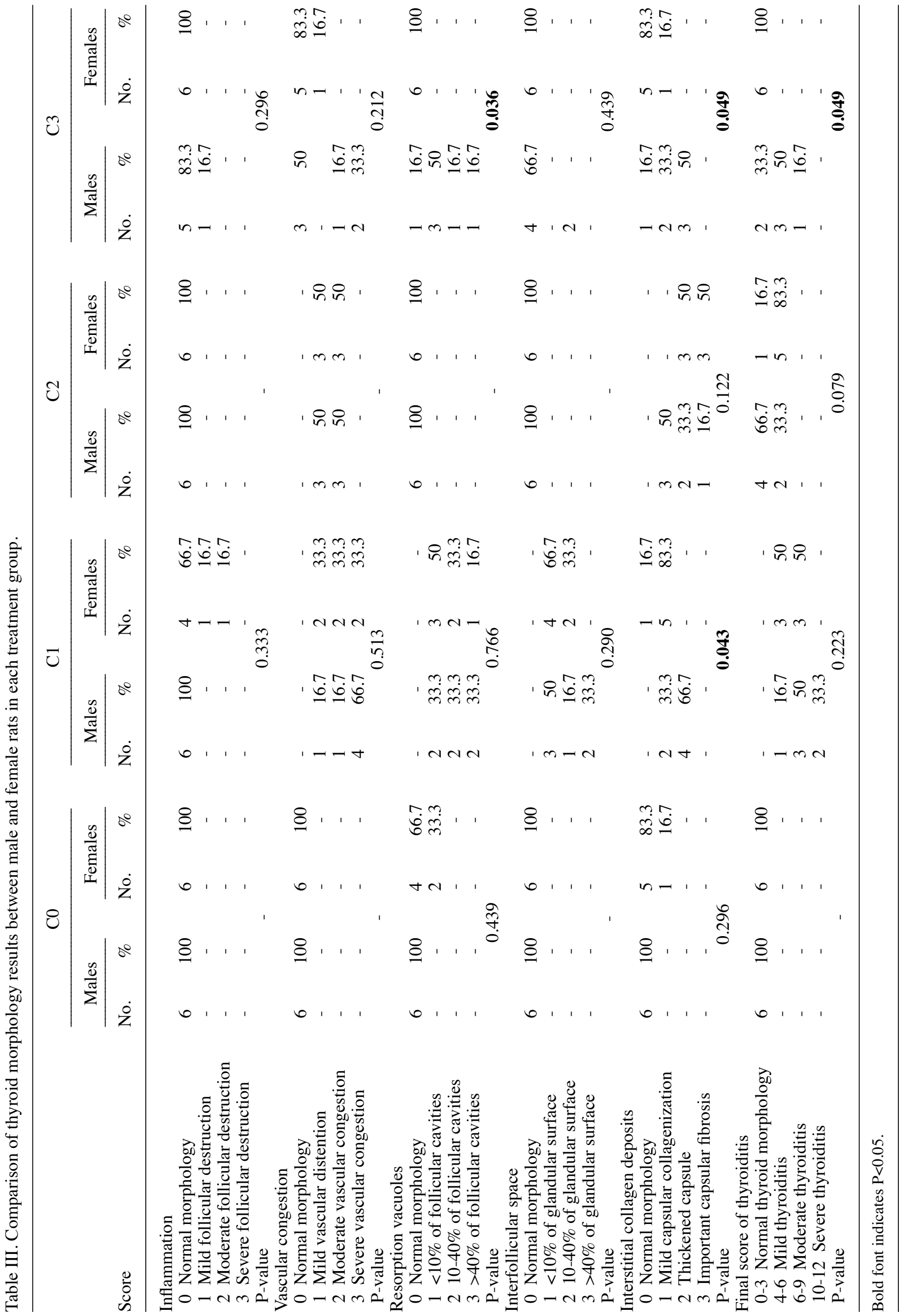


Table IV. Association matrixes of morphopathological parameter results assessed within each study group.

\begin{tabular}{|c|c|c|c|c|c|c|c|c|c|c|}
\hline Males & $\mathrm{C} 1$ & $\mathrm{C} 2$ & $\mathrm{C} 3$ & $\mathrm{CO}$ & Females & $\mathrm{C} 1$ & $\mathrm{C} 2$ & $\mathrm{C} 3$ & $\mathrm{C} 0$ & Males vs. females \\
\hline \multicolumn{11}{|c|}{ Vascular congestion scoring } \\
\hline $\mathrm{C} 1$ & - & & & & $\mathrm{C} 1$ & - & & & & 0.513 \\
\hline $\mathrm{C} 2$ & 0.049 & - & & & $\mathrm{C} 2$ & 0.301 & - & & & - \\
\hline $\mathrm{C} 3$ & 0.020 & 0.029 & - & & $\mathrm{C} 3$ & 0.025 & 0.011 & - & & 0.212 \\
\hline $\mathrm{C} 0$ & 0.001 & 0.002 & 0.050 & - & $\mathrm{C} 0$ & 0.007 & 0.002 & 0.500 & - & - \\
\hline $\mathrm{C} 1+2+3$ & & & & 0.001 & $\mathrm{C} 1+2+3$ & & & & 0.049 & 0.407 \\
\hline \multicolumn{11}{|c|}{ Resorption vacuoles scoring } \\
\hline $\mathrm{C} 1$ & - & & & & $\mathrm{C} 1$ & - & & & & 0.766 \\
\hline $\mathrm{C} 2$ & 0.007 & - & & & $\mathrm{C} 2$ & 0.001 & - & & & - \\
\hline $\mathrm{C} 3$ & 0.661 & 0.036 & - & & $\mathrm{C} 3$ & 0.001 & - & - & & 0.036 \\
\hline $\mathrm{C} 0$ & 0.007 & - & $\mathbf{0 . 0 3 6}$ & - & $\mathrm{C} 0$ & 0.050 & 0.439 & 0.439 & - & 0.439 \\
\hline $\mathrm{C} 1+2+3$ & & & & 0.001 & $\mathrm{C} 1+2+3$ & & & & 0.050 & 0.036 \\
\hline \multicolumn{11}{|c|}{ Interfollicular spaces scoring } \\
\hline $\mathrm{C} 1$ & - & & & & $\mathrm{C} 1$ & - & & & & 0.290 \\
\hline $\mathrm{C} 2$ & 0.007 & - & & & $\mathrm{C} 2$ & 0.002 & - & & & - \\
\hline $\mathrm{C} 3$ & 0.025 & 0.439 & - & & $\mathrm{C} 3$ & 0.002 & - & - & & 0.439 \\
\hline $\mathrm{C} 0$ & 0.007 & - & 0.439 & - & $\mathrm{C} 0$ & 0.002 & - & - & - & - \\
\hline $\mathrm{C} 1+2+3$ & & & & & $\mathrm{C} 1+2+3$ & & & & & \\
\hline \multicolumn{11}{|c|}{ Interstitial collagen deposits scoring } \\
\hline $\mathrm{C} 1$ & - & & & & $\mathrm{C} 1$ & - & & & & 0.043 \\
\hline $\mathrm{C} 2$ & 0.393 & - & & & $\mathrm{C} 2$ & 0.004 & - & & & 0.043 \\
\hline $\mathrm{C} 3$ & 0.497 & 0.439 & - & & $\mathrm{C} 3$ & 0.003 & 0.040 & - & & 0.122 \\
\hline $\mathrm{C} 0$ & 0.002 & 0.007 & 0.014 & - & $\mathrm{C} 0$ & 0.003 & 0.040 & - & - & 0.296 \\
\hline $\mathrm{C} 1+2+3$ & & & & 0.001 & $\mathrm{C} 1+2+3$ & & & & 0.050 & 0.050 \\
\hline \multicolumn{11}{|c|}{ Final thyroiditis scoring } \\
\hline $\mathrm{C} 1$ & - & & & & $\mathrm{C} 1$ & - & & & & 0.223 \\
\hline $\mathrm{C} 2$ & 0.025 & - & & & $\mathrm{C} 2$ & 0.105 & - & & & 0.079 \\
\hline $\mathrm{C} 3$ & 0.049 & 0.393 & - & & $\mathrm{C} 3$ & 0.002 & 0.019 & - & & 0.049 \\
\hline $\mathrm{C} 0$ & 0.007 & 0.439 & 0.049 & - & $\mathrm{C} 0$ & 0.002 & 0.019 & - & - & - \\
\hline $\mathrm{C} 1+2+3$ & & & & 0.046 & $\mathrm{C} 1+2+3$ & & & & 0.033 & 0.474 \\
\hline
\end{tabular}

Bold font indicates $\mathrm{P}<0.05$.

a scoring system from 0 to 3 for each of the following parameters: Presence of inflammation, vascular congestion, resorption vacuoles, interfollicular space and interstitial collagen deposits (Table II). A final thyroiditis score was calculated as the sum of the inflammation score, vascular congestion, fibrosis and resorption vacuoles scores, and the results corresponded to either normal thyroid morphology (final score 0-3), mild thyroiditis (final score 4-6), moderate thyroiditis (final score 7-9) or severe thyroiditis (final score 10-12) (Table II).

Statistical analysis. All statistical analyses were performed using SPSS v24.0 software (IBM Corp.). Skewness and kurtosis $(-2<\mathrm{P}<2)$ tests, the tests of normality in frequentist statistics, were used to examine the distribution of continuous variables. For multiple comparisons of normally distributed data, two-way ANOVA was performed with Tukey's HSD post hoc test. If the normality assumption was not satisfied,
Kruskal-Wallis test and Dunn-Bonferroni post hoc test were carried out. Associations between categorical variables were assessed by Chi-square test.

The results are presented in Tables III and IV and Figs. 1 and 2. Specifically, Figs. 1 and 2 present the data on thyroid morphofunctional parameters, i.e., the mean size of thyroid follicles and follicular epithelium. Table III presents the comparison of the thyroid morphology results between male and female rats in each treatment group. Association matrixes of the morphopathological parameters assessed within each study group are presented in Table IV (vascular congestion, resorption vacuoles, interfollicular space, interstitial collagen deposits).

\section{Results}

Mean size of thyroid follicles. Regarding the size of thyroid follicles, the normality tests revealed the following aspects: 


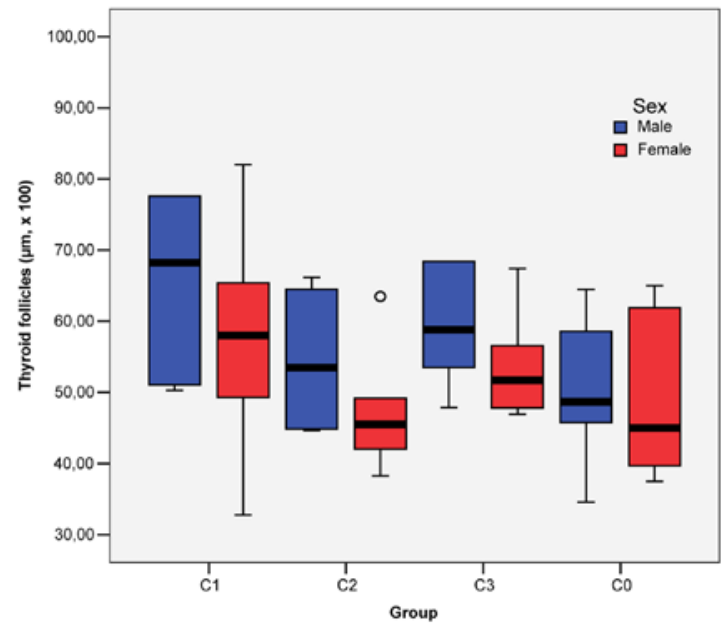

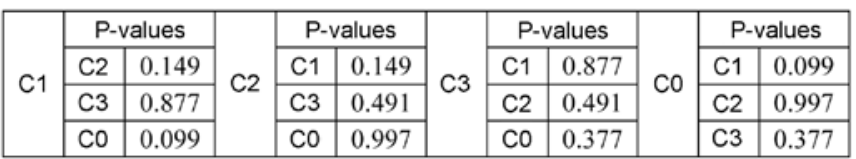

Figure 1. Comparison of the mean value of thyroid follicles $(\mu \mathrm{m}, \mathrm{x} 100)$ evaluated by sex between the study groups (median values are indicated by a bold line for each group).

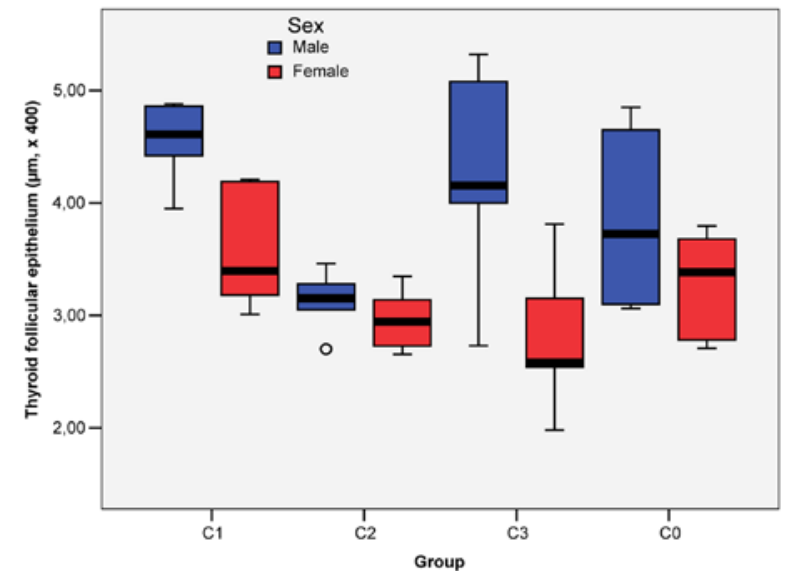

\begin{tabular}{|c|c|c|c|c|c|c|c|c|c|c|c|}
\hline \multirow{4}{*}{ C1 } & \multicolumn{2}{|c|}{$\mathrm{P}$-values } & \multirow{4}{*}{$\mathrm{C} 2$} & \multicolumn{2}{|c|}{$\mathrm{P}$-values } & \multirow{4}{*}{ C3 } & & alues & \multirow{4}{*}{ CO } & \multicolumn{2}{|c|}{$\mathrm{P}$-values } \\
\hline & $\mathrm{C} 2$ & 0.001 & & C1 & 0.001 & & C1 & 0.104 & & C1 & 0.177 \\
\hline & C3 & 0.104 & & C3 & 0.220 & & $\mathrm{C} 2$ & 0.220 & & $\mathrm{C} 2$ & 0.133 \\
\hline & $\mathrm{CO}$ & 0.177 & & $\mathrm{CO}$ & 0.133 & & $\mathrm{CO}$ & 0.993 & & C3 & 0.993 \\
\hline
\end{tabular}

Figure 2. Comparison of the mean value of thyroid follicular epithelium $(\mu \mathrm{m}, \mathrm{x} 400)$ evaluated by sex between the study groups (median values are indicated by a bold line for each group). Values in bold correspond to $\mathrm{P}<0.05$.

The analysis of the entire study group showed that the mean value $(56.48 \pm 17.05 \mu \mathrm{m} \times 100)$ was far different than the median value $(52.40 \mu \mathrm{m} \times 100)$; Skewness $(\mathrm{skw}=2.105)$ and Kurtosis $(\mathrm{krt}=6.605)$ test results $>2$ suggested that the assumption of normality was not satisfied for the entire range of values; however, in $\mathrm{C} 0, \mathrm{C} 1, \mathrm{C} 3$, for both male and female subgroups, continuous values were confirmed.

The male rat thyroid morphology (Figs. 1, and 3A and B) showed that $\mathrm{C} 1$ group had higher mean value of thyroid follicles than $\mathrm{C} 0$ group (73.82 vs. $50.13 \mu \mathrm{m} \times 100)$ and $\mathrm{C} 2$ group (73.82 vs. $53.74 \mu \mathrm{m} \times 100)$. In $\mathrm{C} 3$ group, the mean value was higher than that recorded in the control group
A

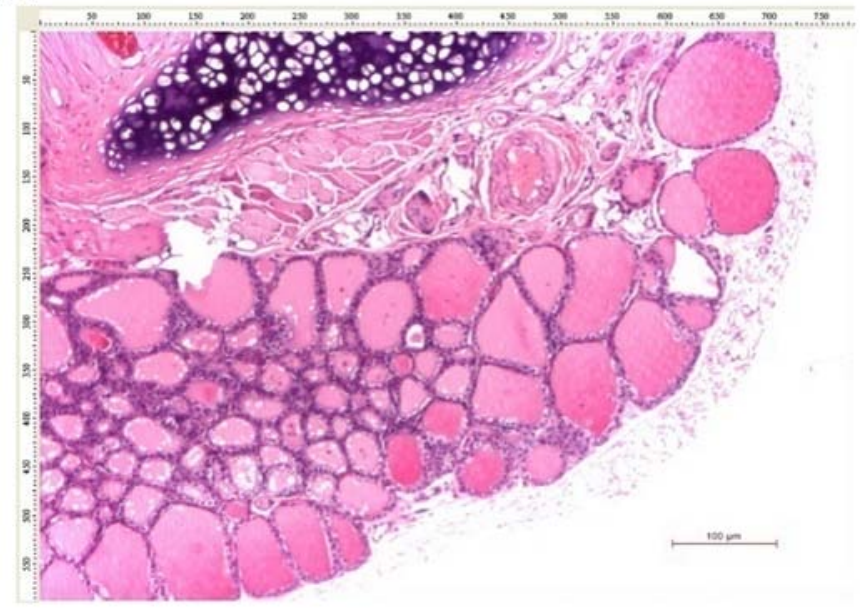

B

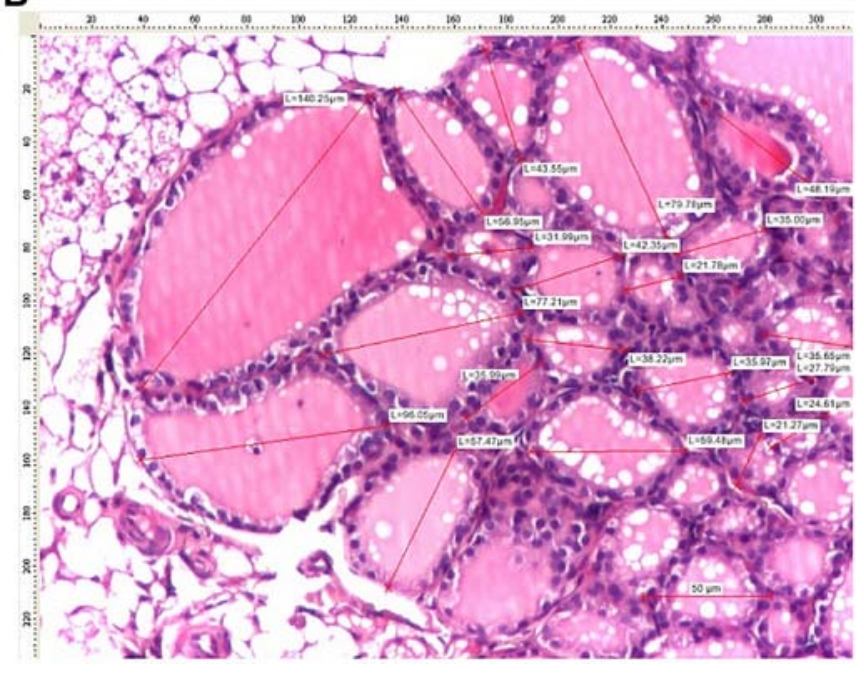

C

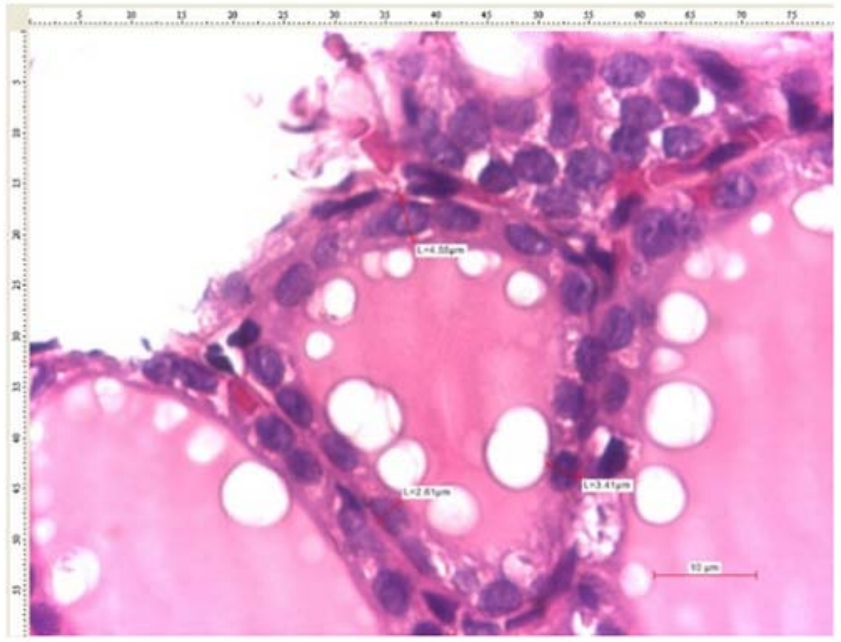

Figure 3. Thyroid images of male rats with KI administration. (A) Thyroid tissue $(H \& E, x 4),(B)$ measurements of the maximum diameter of 20 thyroid follicles $(\mathrm{H} \& \mathrm{E}, \mathrm{x} 10)$ and $(\mathrm{C})$ measurements of follicular epithelium heights $(\mathrm{H} \& \mathrm{E}, \mathrm{x} 40) . \mathrm{KI}$, potassium iodine; H\&E, hematoxylin and eosin.

C0 (65.86 vs. $50.13 \mu \mathrm{m} \times 100)$. The lowest mean value of the thyroid follicles was registered in the control group C0 (Fig. 1). 
A

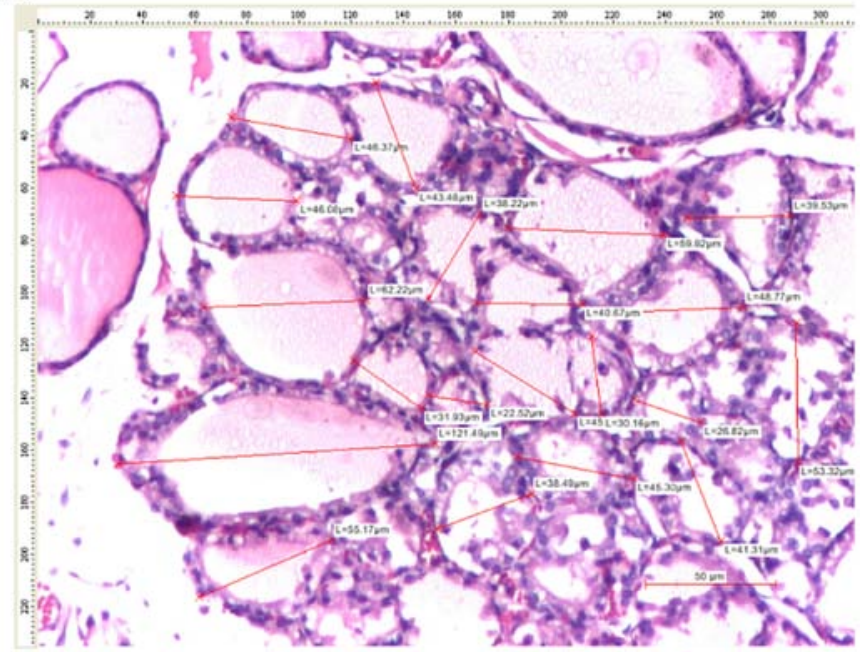

C

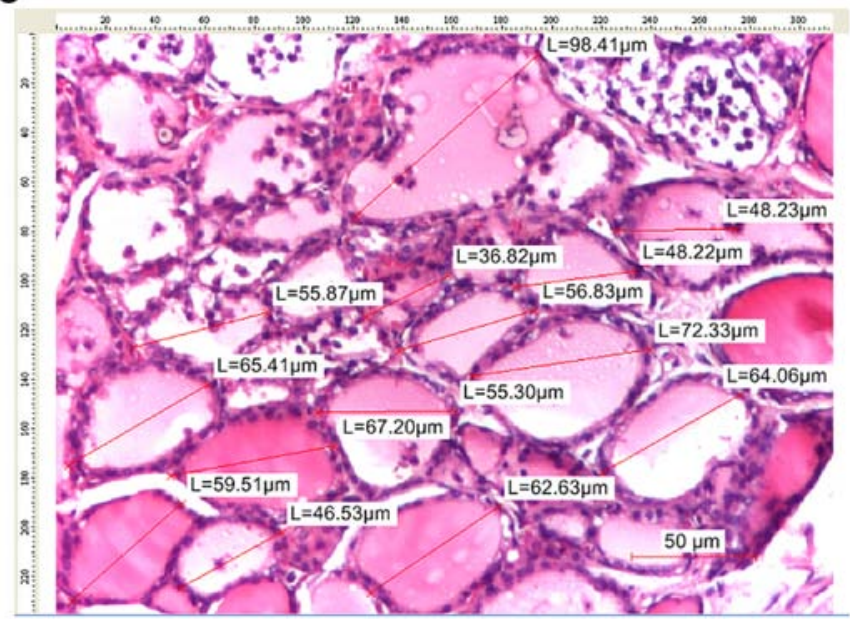

B

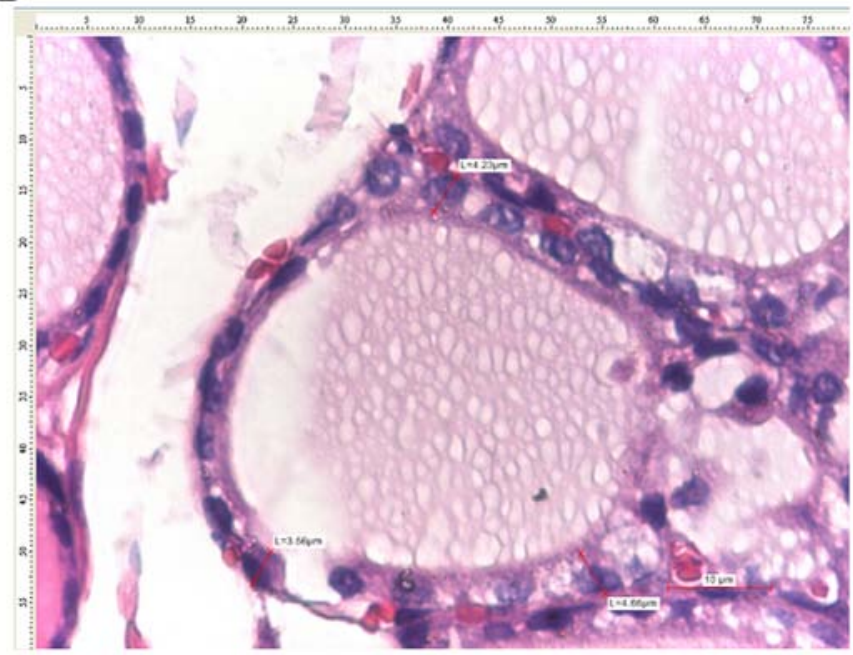

D

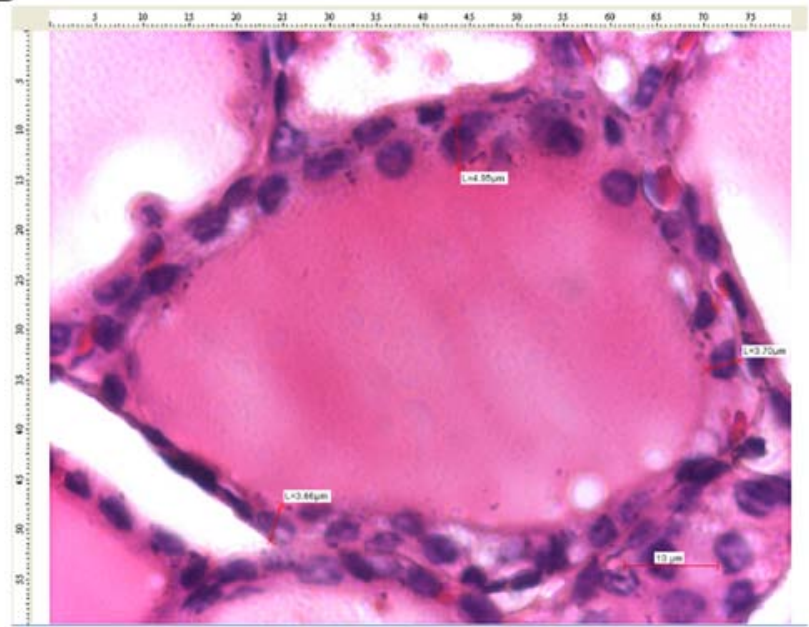

Figure 4. Thyroid images of female rats with concomitant KI and sodium selenite administration. Measurements of (A) the maximum diameter of thyroid follicles (H\&E, x10) (20 thyroid follicles were measured in total) and (B) follicular epithelium heights (H\&E, x40). Comparison with the control group: (C) maximum diameter of thyroid follicles (H\&E, x10) (20 thyroid follicles were measured in total) and (D) follicular epithelium heights (H\&E, $\mathrm{x} 40$ ). KI, potassium iodine; $\mathrm{H} \& \mathrm{E}$, hematoxylin and eosin.

In female rats, the highest mean value of thyroid follicles was recorded in $\mathrm{C} 1$ group $(57.56 \mu \mathrm{m} \times 100)$ and the lowest in C2 group (47.32 $\mu \mathrm{m} \times 100$; Figs. 1 and $4 \mathrm{~A}$ and $\mathrm{C}, 7 \mathrm{~B}$, and $8 \mathrm{~B})$.

The results of two-way ANOVA showed no statistically significant differences in the mean size of thyroid follicles analyzed by sex and intervention group (Fig. 1).

Mean size of the thyroid follicular epithelium. The values for the size of follicular epithelium in the entire study group were homogeneous, thus significance tests could be applied for these continuous variables: The mean value $(3.55 \pm 0.80 \mu \mathrm{m} \mathrm{x} 400)$

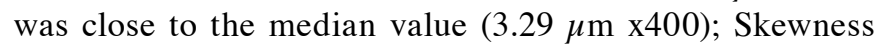
$(\mathrm{skw}=0.472)$ and Kurtosis $(\mathrm{krt}=-0.649)$ test results were comprised in the interval $[-2,+2]$.

In male rats, the highest mean value of the thyroid follicular epithelium was recorded in $\mathrm{C} 1$ group (only $\mathrm{KI}$ administration; $4.56 \mu \mathrm{m} \times 100)$ and the lowest mean value in $\mathrm{C} 2$ group $(3.13 \mu$ $\mathrm{m} \times 100$ ) (Figs. 3C and 5B).

In female rats, the highest mean value of the thyroid follicular epithelium was recorder in $\mathrm{C} 1$ group $(3.56 \mu \mathrm{m}$ $\mathrm{x} 100)$ and the lowest mean value was recorded in C3 group (2.77 $\mu \mathrm{m} \times 100)$ (Figs. 2, 4B and D, 7C and E, and 8C).

Two-way ANOVA results showed statistically significant differences in the mean size of thyroid follicular epithelium analyzed by sex and intervention group only between $\mathrm{C} 1$ (only KI adminsitration) and $\mathrm{C} 2$ (concomitant KI and sodium selenite administration) groups (Fig. 2).

Inflammation assessment. The results on thyroid inflammation revealed that there were no significant differences between sex or treatment regimens in the study groups $(\mathrm{C} 1, \mathrm{P}=0.333$; $\mathrm{C} 3$, $\mathrm{P}=0.296$; Table III).

Vascular congestion. In male rats, significant differences were found between groups: In $\mathrm{C} 1$ group, severe vascular congestion was observed in $66.7 \%$ of male rats; in $\mathrm{C} 2$ group, $50 \%$ of rats had moderate vascular congestion; whereas in $\mathrm{C} 3$ group, $50 \%$ of male rats had normal vascular morphology ( $\mathrm{P}=0.001$; Table III).

In female rats, significant differences were also identified between groups: In $\mathrm{C} 1$ group, the same percentage of 
A

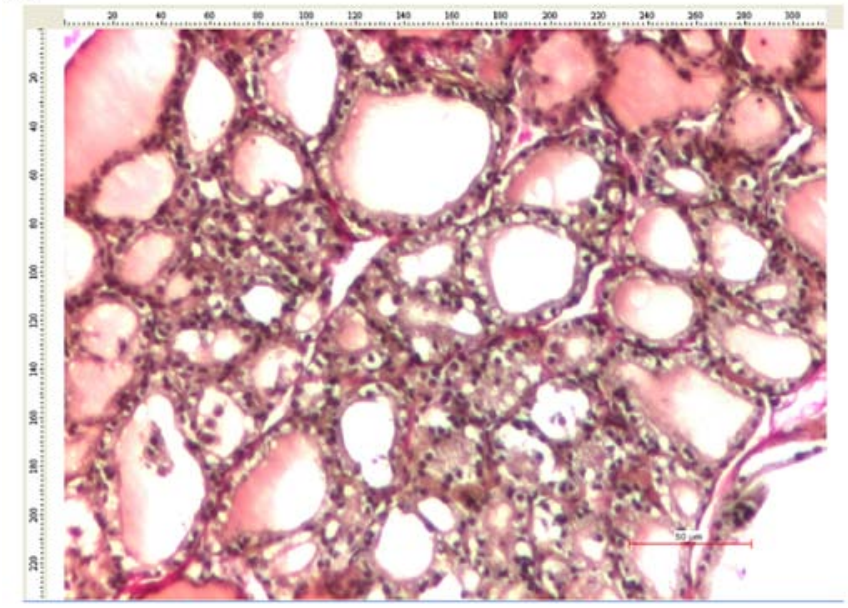

B

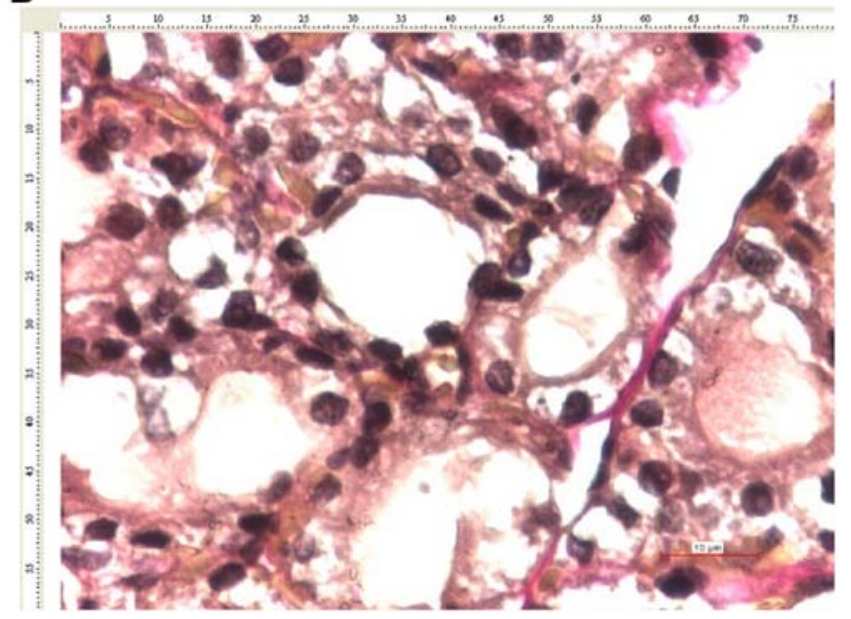

Figure 5. Images of KI-induced thyroiditis in male rats. (A) Fibrosis, inflammation, vascular congestion and resorption vacuoles (VG, x20) and (B) follicular epithelium details (VG, x40). KI, potassium iodine; VG, van Gieson's stain.

A

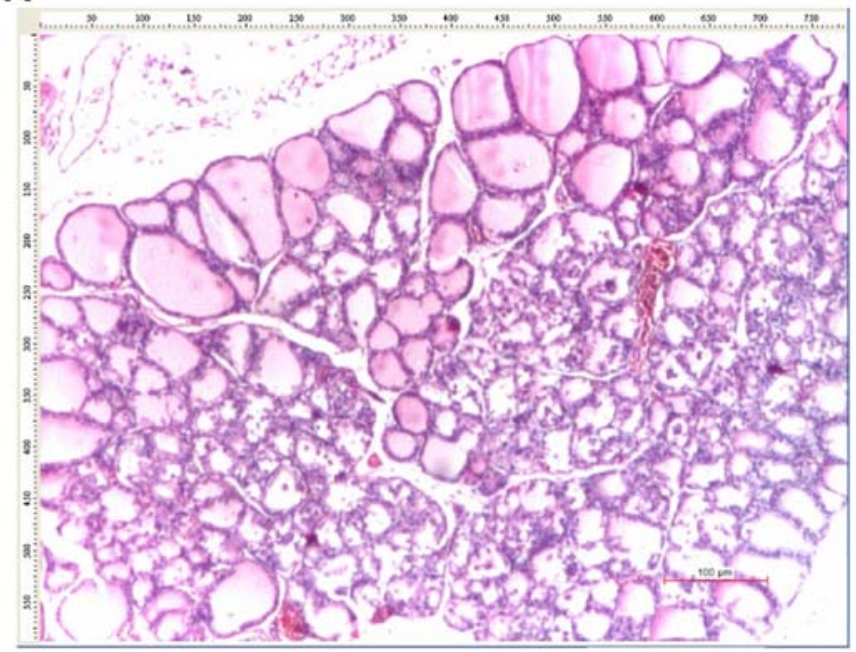

B

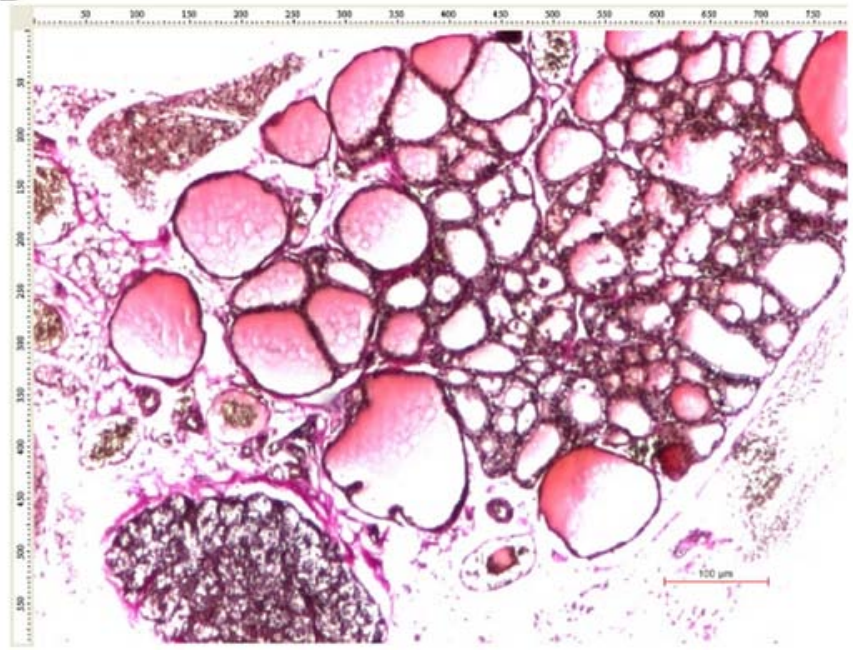

Figure 6. Thyroid images of female rats with concomitant KI and sodium selenite administration. Thyroid tissue stained with (A) H\&E (x4) and (B) VG (x4), KI, potassium iodine; H\&E, hematoxylin and eosin; VG, van Gieson's stain.

cases $(33.3 \%)$ presented severe, moderate and mild vascular modifications; in $\mathrm{C} 2$ group, $50 \%$ of female rats had moderate vascular congestion; whereas in $\mathrm{C} 3$ group, $83.3 \%$ of the cases had normal vascular morphology $(\mathrm{P}=0.049)$. However, within each of the study groups, no statistically significant differences in terms of sex were confirmed $(\mathrm{C} 1, \mathrm{P}=0.513 ; \mathrm{C} 3, \mathrm{P}=0.212$; Tables III and IV).

Resorption vacuoles. In male rats, significant differences were confirmed between the groups: In $\mathrm{C} 1$ group, resorption vacuoles assessment revealed equal percentages of cases (33.3\%) with score $1(<10 \%), 2(10-40 \%)$ and $3(>40 \%)$; in C2 group, all cases had normal morphology; and in $\mathrm{C} 3$ group, $50 \%$ of the male rats had resorption vacuoles $<10 \%(\mathrm{P}=0.001$; Table III).

In female rats, significant differences were also found between groups: $\mathrm{In} \mathrm{C} 1$ group, $50 \%$ of female rats had resorption vacuoles $<10 \%$; and in $\mathrm{C} 2$ and $\mathrm{C} 3$ groups, all cases had normal morphology ( $\mathrm{P}=0.05$; Tables IV and 7D). Significant sex differences were observed only in $\mathrm{C} 3$ group ( $\mathrm{P}=0.036$; Table III).
Interfollicular space. All rats (regardless of sex) in $\mathrm{C} 1$ group (only KI administration) presented interfollicular spaces. The interfollicular space score for $\mathrm{C} 1$ male rats (treated only with KI) was significantly different than that in $\mathrm{C} 2$ group (concomitant $\mathrm{KI}$ and Se administration, $\mathrm{P}=0.007$ ), $\mathrm{C} 3$ group (subsequent $\mathrm{KI}$ and $\mathrm{Se}$ administration, $\mathrm{P}=0.025)$ and $\mathrm{C} 0$ group (control, $\mathrm{P}=0.007$ ) (Table IV). Scores of 2 (10-40\% of glandular surface) and 3 ( $>40 \%$ of glandular surface) were particularly recorded in $50 \%$ of male rats (one rat with score 2 and two rats with score 3 ), whereas all the female rats presented only scores of $1(<10 \%$ of the glandular surface) and 2 (Table III).

Interstitial collagen deposits. In male rats, $66.7 \%$ of the cases in the $\mathrm{C} 1$ group had moderate fibrosis; in $\mathrm{C} 2$ group, $50 \%$ of male rats had mild collagen deposits and only $33.3 \%$ moderate fibrosis; whereas in C3 group, only $33.3 \%$ of cases had mild collagen deposits and $50 \%$ moderate fibrosis ( $\mathrm{P}=0.001$; Table III).

In female rats, significant differences between groups were also confirmed: In $\mathrm{C} 1$ group, $83.3 \%$ of the rats had 


\section{A}

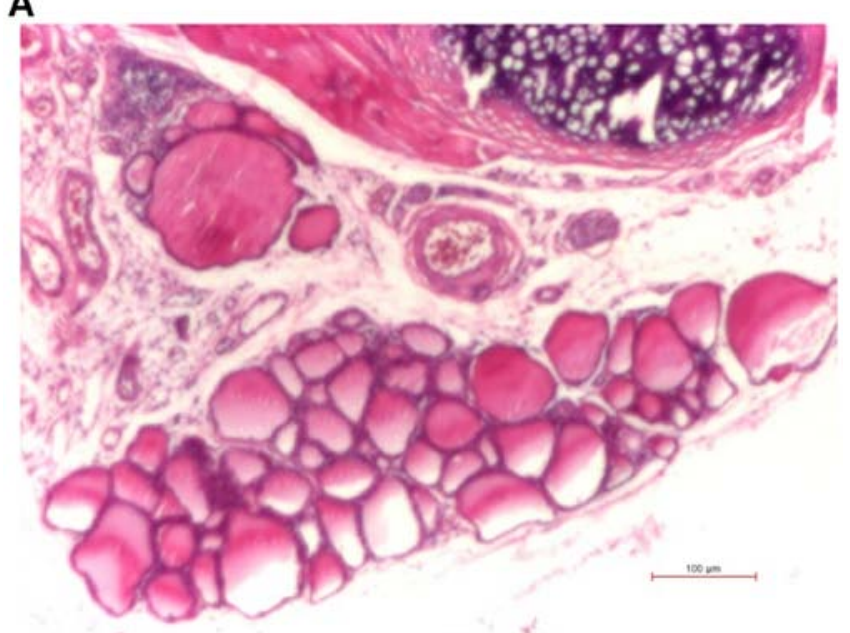

C

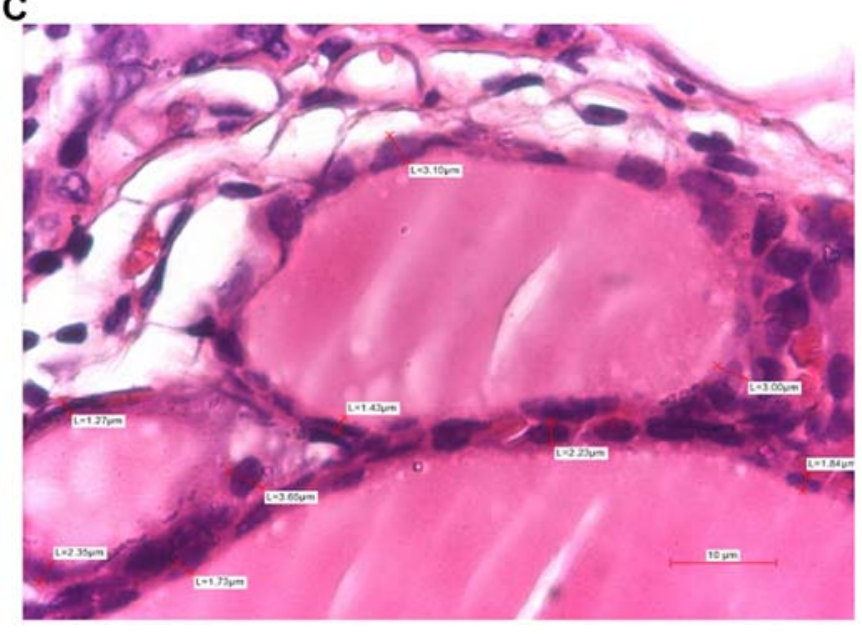

B

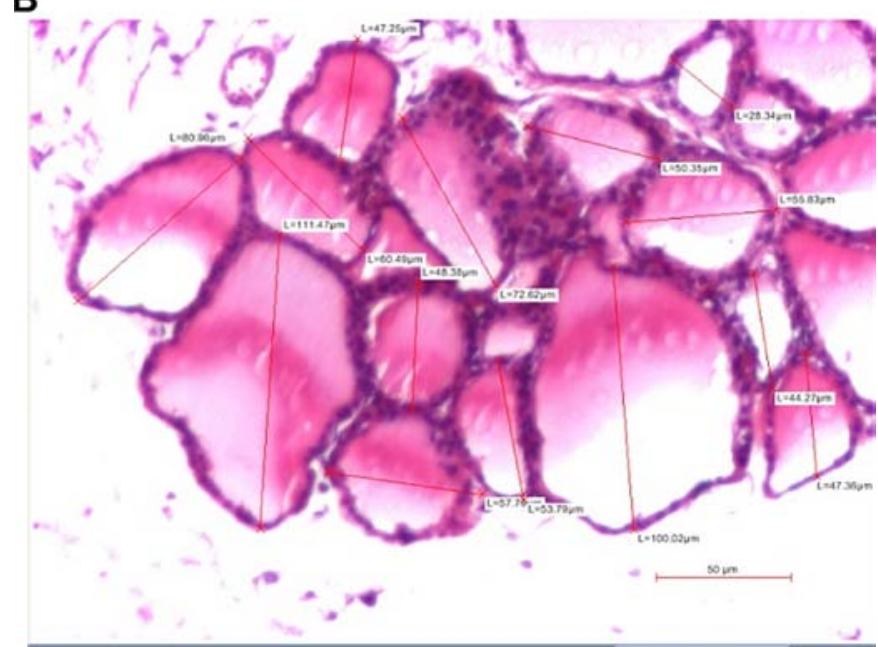

D

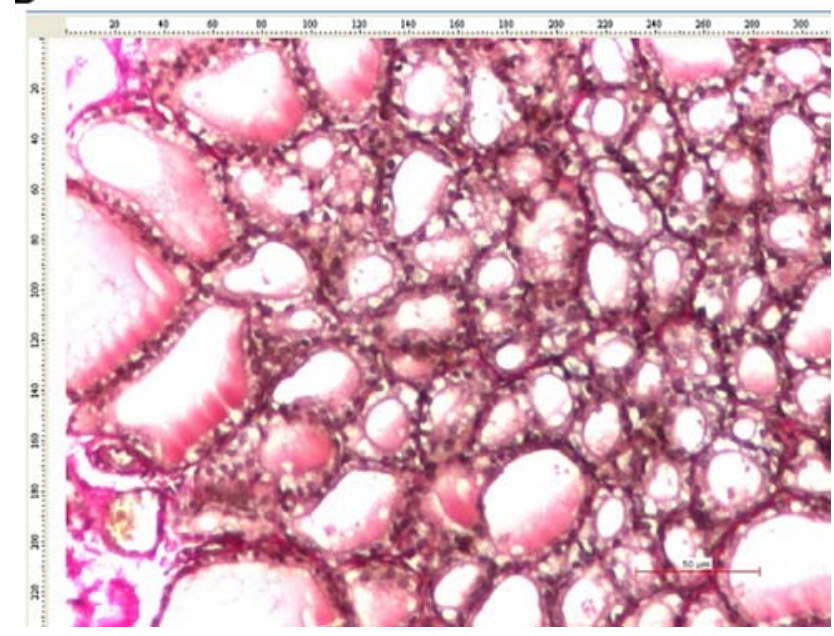

$\mathbf{E}$

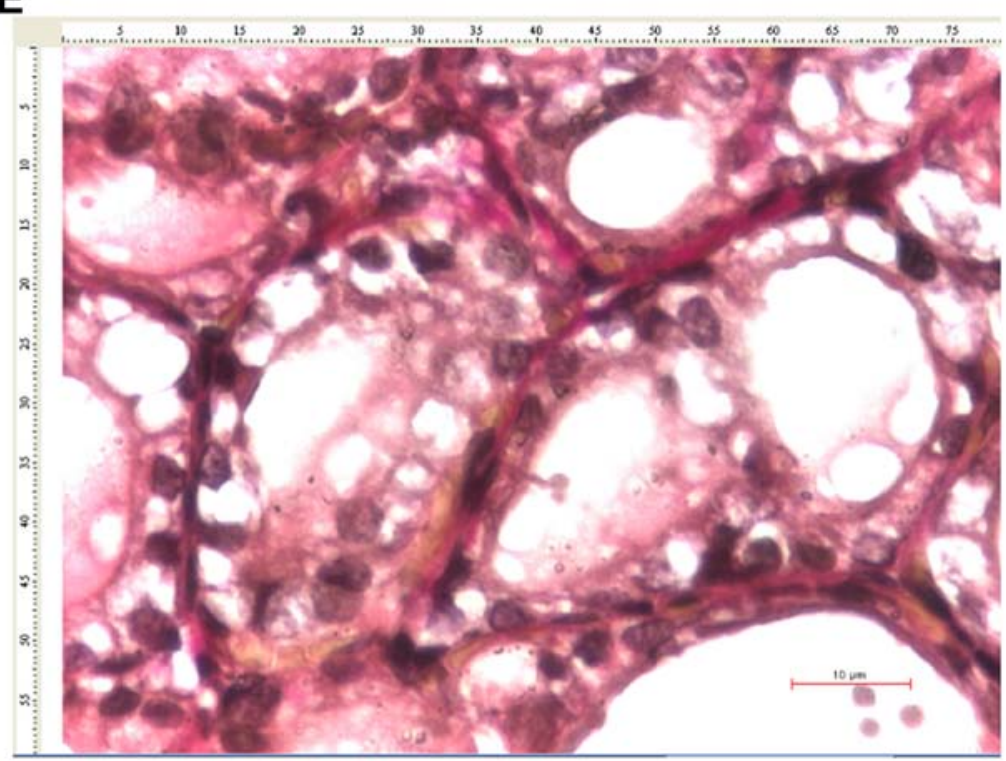

Figure 7. Thyroid images of female rats with sequential administration of KI and sodium selenite. (A) Thyroid tissue (H\&E, x4), (B) measurements of the maximum diameter of thyroid follicles (H\&E, x10) (20 thyroid follicles were measured in total), (C) measurements of follicular epithelium heights (H\&E, 440$)$, (D) resorption vacuoles (VG, x20) and (E) follicular epithelium details (VG, x40). KI, potassium iodine; H\&E, hematoxylin and eosin; VG, van Gieson's stain.

discrete collagen deposits; in C2 group, $50 \%$ had important collagen deposits; and in C3 group, $83.3 \%$ had normal morphology ( $\mathrm{P}=0.05$; Table IV). Concerning the morphology of interstitial collagen deposits, significant sex differences 
A

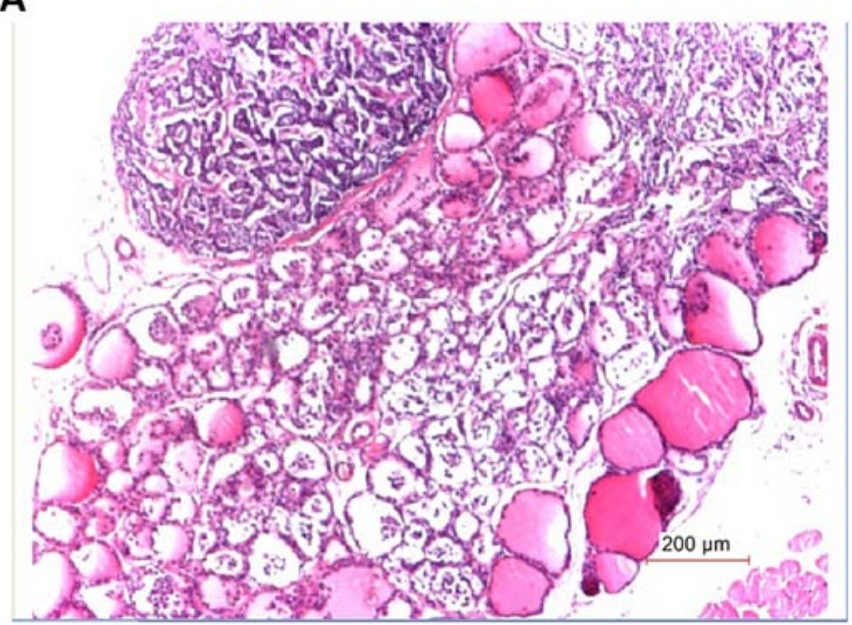

B

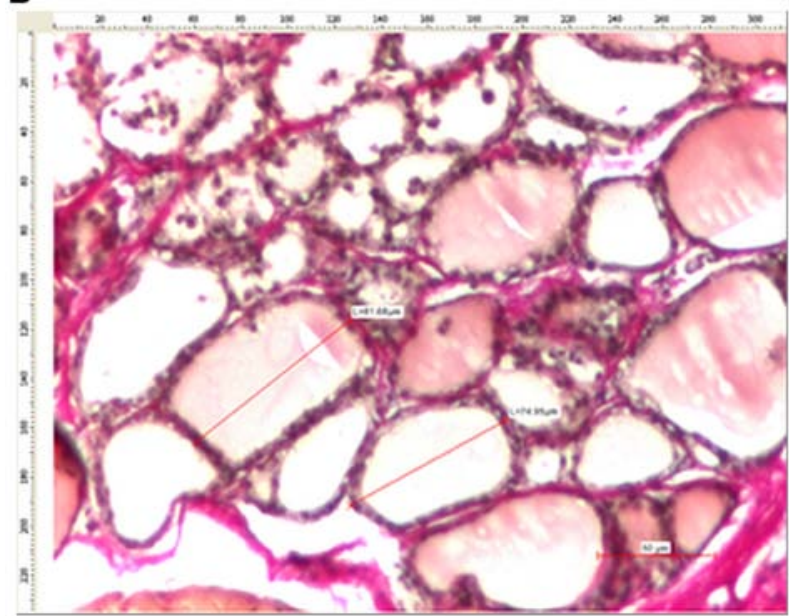

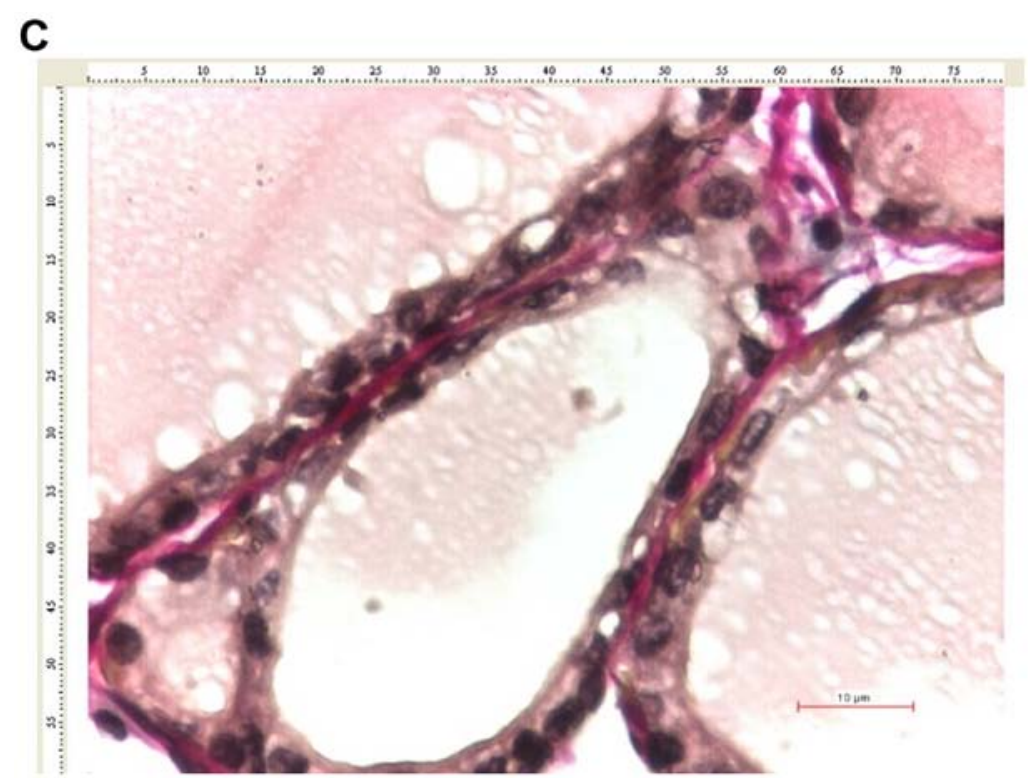

Figure 8. Thyroid images of female control rats. (A) Thyroid and parathyroid tissue (H\&E, x4), (B) measurements of the maximum diameter of thyroid follicles $(\mathrm{VG}, \mathrm{x} 10)(20$ thyroid follicles were measured in total) and (C) follicular epithelium details (VG, x40). H\&E, hematoxylin and eosin; VG, van Gieson's stain.

were observed only within $\mathrm{C} 1(\mathrm{P}=0.043)$ and $\mathrm{C} 3(\mathrm{P}=0.049)$ groups (Table III).

Thyroiditis final score. In males, significant differences between treatment regimens were confirmed: In $\mathrm{C} 1$ group (only KI administration), $50 \%$ of the rats developed moderate thyroiditis and $33.3 \%$ severe thyroiditis; in $\mathrm{C} 2$ group (concomitant $\mathrm{KI}$ and Se administration), 33.3\% of the male rats developed mild thyroiditis; and in $\mathrm{C} 3$ group (subsequent $\mathrm{KI}$ and Se administration), 50\% of cases had mild thyroiditis and $16.7 \%$ moderate thyroiditis $(\mathrm{P}=0.046$; Table IV and Fig. 5A).

Female rats demonstrated significant differences in overall thyroid morphology: In $\mathrm{C} 1$ group, 50\% of cases developed moderate thyroiditis; in $\mathrm{C} 2$ group, $83.3 \%$ of female rats had mild thyroiditis; whereas all cases in $\mathrm{C} 3$ group had normal morphology ( $\mathrm{P}=0.033$; Table IV and Figs. 6A and 7A).

Regarding final thyroiditis score, significant sex differences were recorded only in $\mathrm{C} 3$ group where all females had normal thyroid morphology, similar to the female control group ( $\mathrm{P}=0.049$; Table III and Fig. 8A).

\section{Discussion}

In the present study, the protective role of Se on thyroid morphology in iodine-induced AIT in Wistar rats was confirmed. Se effect was more evident in female rats, as the subsequent administration of Se after iodine exposure determined minimum modifications on the thyroid morphology, preserving the normal aspect of the thyroid gland.

Iodine plays an important role in the induction and modulation of thyroid autoimmunity. Several studies have assessed the prevalence of thyroid antibodies and autoimmune hypothyroidism in patients which are located in iodine-replete versus in iodine-deficient areas (25-27).

After iodine prophylaxis in iodine deficient areas, a 4-fold increase in the prevalence of anti-thyroid antibodies has been reported (28). According to a Danish survey, following the administration of $500 \mu \mathrm{g} /$ day iodine dose for 6 months, AIT occurred in $20 \%$ of the healthy individuals that were included in the study (29).

The same results were obtained using NOD.H $2^{\mathrm{h} 4}$ mice as experimental animal models for genetically determined AIT. 
Iodine enrichment in these mice showed increased incidence and severity of the disease in a dose-dependent manner (1). Several possible mechanisms have been described by which iodine could trigger AIT. Iodine exposure leads to increased iodination of thyroglobulin and, therefore, to increased antigenicity (immunogenicity) by creating new iodine-containing epitopes or by discovering cryptic epitopes. This facilitates antigen exposure (antigen processing or antigen presentation) and, thus, increases $\mathrm{T}$ cell receptor binding and activation of $\mathrm{T}$ cells, respectively (1).

Secondly, increased iodine exposure determines the increase of reactive oxygen species (ROS) in thyrocytes. ROS may increase the expression of intracellular adhesion molecule 1 in the thyroid follicular cell, which subsequently attracts immunocompetent cells to the thyroid gland. The binding of ROS to the phospholipidic membrane may induce injury to the thyroid and the release of auto-antigens (28). In addition, iodine excess promotes apoptosis of thyroid follicular cells by inducing the expression of TRAIL (TNF-related apoptosis-inducing ligand) necrosis factor and its receptor, death receptor-5, in the thyroid. There is also in vitro evidence of the iodine's influence on the immune system cells as it may increase dendritic cell maturation, and increase the number of $\mathrm{T}$ cells, as well as the production of immunoglobulins (28).

In the present study, the EAT in adult male and female Wistar rats was induced by $\mathrm{KI}$ administration in the drinking water. Most studies in the literature, which sought to induce AIT, used genetically modified animal models, NOD.H2 $2^{\mathrm{h} 4}(1,13)$ and $\mathrm{BB} / \mathrm{W}$ (Bio Breeding/Worcester) rats $(30,31)$. NOD mice and $\mathrm{BB} / \mathrm{W}$ rats are animal models generally used for the study of type 1 diabetes. NOD.H2 $2^{\text {h4 }}$ is a genetically animal model predisposed to develop AIT over time. Iodine administration increases the prevalence of AIT, earlier occurrence, and a more severe form of disease (32). A similar study was performed on $\mathrm{BB} / \mathrm{W}$ rats by looking at the effect of excess iodine on thyroid function and on immunological phenomena that trigger AIT. The results of the study showed an increase in the number of dendritic cells and lymphocyte infiltrate in animals receiving additional iodine in drinking water (31). Both the increase in the number of dendritic cells and the lymphocyte infiltrate are possible mechanisms involved in triggering AIT.

In a study on NOD.H $2^{\mathrm{h} 4}$ mice of different ages, it was observed that the prevalence and severity of AIT increased with age in genetically predisposed animals (32). In the present study, only young adult Wistar rats were used, with no genetic predisposition to influence the onset or the form of the disease. This was also preferred in order to have a homogenous group and to avoid possible age-induced changes in the experiment.

Regarding the presence of thyroid inflammation in both male and female Wistar rats, no significant changes between the treatment regimens were described, the results being similar to those in the control group. The absence of inflammation could be explained by the short period of iodine administration or by insufficient iodine quantities. Similar studies that obtained inflammatory changes had administered iodine up to 12 weeks (32-34).

The evolution of follicular epithelioum size shows potential benefits of Se treatment as favourable statistically significant differences were observed between the measured parameter in the group treated with concomitant sodium selenite and KI administration, in comparison with the group administered with only iodide.

Significant changes were observed in the groups treated with KI and Se compared with the KI treated groups, with forms of thyroiditis less aggressive in both males and females treated with Se. In rats with sequentially KI and sodium selenite administration, the same favourable outcomes were not obtained as in the case of the concomitantly treated groups; this effect was only observed in males. The females initially treated with KI and subsequently with Se had a surprising evolution, the results being almost identical to those of the control group, as they no longer had AIT. Experimental studies have shown that the antigen that initiates AIT in animal models is thyroglobulin, regardless of species (studies in mice, rats and birds) (35). The thyroglobulin allografts affect the susceptibility to thyroiditis. Moreover, modulating genes related to the X-chromosome have been highlighted, which could explain the different responses in AIT not only in animals, but also in humans (36). The effectiveness of Se supplementation proved to be different depending on the time of treatment initiation and sex.

Autoimmune thyroid disease is highly prevalent, with the highest female-to-male ratio among all autoimmune diseases (37). There is a large body of evidence that moderate amounts of estrogen may enhance immunologic reactivity to self-antigens $(38,39)$. However, as AIT is frequently diagnosed after menopause, the X-chromosome seems to be the source of enhanced susceptibility rather than sex steroid levels. For example, $\mathrm{X}$-chromosome inactivation has been associated with autoimmune thyroid disease (40). However, there have been reports in men that confirm a connection between estradiol levels (or estradiol to testosterone ratio) and thyroid autoimmunity $(41,42)$.

In males, Se supplementation has been shown to be more effective with concomitant administration of KI. Males have been presented with less aggressive forms of the disease than those who had received successive administration (initially with KI and subsequently with Se). Se administration, in both concomitant and then successively treated groups, contributed to milder forms of AIT, compared with the group not supplemented with Se.

Moreover, an extremely important aspect was observed in the groups of female rats in which, unlike male rats, $\mathrm{Se}$ supplementation proved to be very effective. In the group of females treated successively, the thyroid morphological aspect was identical to the morphological appearance of the control group, which did not show AIT, thus advocating the remission of the KI-induced disease. Concomitant administration resulted in a significant improvement in thyroid morphology.

Overall, the results of the present study revealed the effectiveness of Se supplementation in both co-administration with $\mathrm{KI}$ and sequential administration in female and male sex alike. Significant sex differences were recorded in the groups initially treated with $\mathrm{KI}$ and subsequently with $\mathrm{Se}(\mathrm{P}=0.049)$ : While in females histological appearance of the thyroid was normal in the whole group, in males only $33 \%$ had normal thyroid, the rest having mild $(50 \%)$ or medium $(17 \%)$ thyroiditis. In the rest of the study groups, the differences were not statistically significant (Table III). 
This was especially observed in females due to the hormonal features involved in the AIT pathogenesis. It is known that estrogen increases (while androgen decreases) the response of the hypothalamic-pituitary-adrenocortical axis to stress, and activation of this axis is more pronounced in women than in men, which explains the higher incidence of autoimmune thyroid disease in women (43).

There is a number of limitations in the present study. A low number of Wistar rats was used in each study group, although valid for statistical analysis following previous scientific research protocols. In addition, a Se dose-finding study was not performed; however, no clinical signs of Se toxicity were observed during the study at the administered dosages. An additional limitation is represented by the fact that all histopathological sections and the acquisition of images of the studied animals were performed by a single examiner and no Cohen's kappa could be established to confirm the rater's reliability.

The present study showed the effective results of Se supplementation on restoring the normal thyroid morphology in iodine induced AIT in Wistar rats.

In conclusion, the impact of induction of AIT on Wistar rats (induced by $\mathrm{KI}$ administration) is higher in males than in females, although the latter are more prone to the disease. Males develop more severe forms; the difference is primarily due to the modulating role of estrogens.

Se supplementation has been shown to be effective, resulting in improved forms of AIT. The timing of Se administration has also been proven to be important and concomitant administration of KI and sodium selenite is associated with the return of thyroid morphology to normal in most cases.

\section{Acknowledgements}

Professional editing, linguistic and technical assistance was provided by Irina Radu, Individual Service Provider, certified translator in Medicine and Pharmacy (certificate credentials: Series E, no. 0048).

\section{Funding}

The study was supported by an internal grant from 'Grigore T. Popa' University of Medicine and Pharmacy (Iasi, Romania) (no. 29.243/20.12.2013). The funders had no role in the study design, data collection and analysis, decision to publish, or preparation of the manuscript.

\section{Availability of data and materials}

All data generated or analyzed during the study are included in this published article.

\section{Authors' contributions}

CP, DGCA, IV, OB and ILS were involved in the conception and design of the study. CP, DGCA, IV and OB acquired the data. DGCA was involved in the analysis and interpretation of the histological data. The statistical analysis and overall interpretation of data was performed by CP, DGCA, IV, IA and ILS . IV, IA, DGCA and CP drafted the manuscript. CP, DGCA, IV and IA revised critically the manuscript. All authors read and approved the final version of the manuscript.

\section{Ethics approval and consent to participate}

The study was approved by the Ethics Committee of 'Grigore T. Popa' University of Medicine and Pharmacy (Iasi, Romania).

\section{Patient consent for publication}

Not applicable.

\section{Competing interests}

The authors declare that they have no competing interests.

\section{References}

1. Rose NR, Bonita R and Burek CL: Iodine: An environmental trigger of thyroiditis. Autoimmun Rev 1: 97-103, 2002.

2. Markou K, Georgopoulos N, Kyriazopoulou V and Vagenakis AG: Iodine-induced hypothyroidism. Thyroid 11: 501-510, 2001.

3. Foley TP Jr: The relationship between autoimmune thyroid disease and iodine intake: A review. Endokrynol Pol 43): 53-69, 1992.

4. Wolff J and Chaikoff IL: Plasma inorganic iodide as a homeostatic regulator of thyroid function. J Biol Chem 174: 555-564, 1948.

5. Paul T, Meyers B, Witorsch RJ, Pino S, Chipkin S, Ingbar SH and Braverman LE: The effect of small increases in dietary iodine on thyroid function in euthyroid subjects. Metabolism 37: 121-124, 1988.

6. Denef JF, Many MC and van den Hove MF: Iodine-induced thyroid inhibition and cell necrosis: Two consequences of the same free-radical mediated mechanism? Mol Cell Endocrinol 121: 101-103, 1996.

7. Vitale M, Di Matola T, D'Ascoli F, Salzano S, Bogazzi F, Fenzi G, Martino E and Rossi G: Iodide excess induces apoptosis in thyroid cells through a p53-independent mechanism involving oxidative stress. Endocrinology 141: 598-605, 2000.

8. Cardoso LC, Martins DCL, Figueiredo MDL, Rosenthal D, Vaisman M, Violante AHD and Carvalho DP: $\mathrm{Ca}(2+) /$ nicotinamide adenine dinucleotide phosphate-dependent $\mathrm{H}(2) \mathrm{O}(2)$ generation is inhibited by iodide in human thyroids. J Clin Endocrinol Metab 86: 4339-4343, 2001.

9. Mahmoud I, Colin I, Many MC and Denef JF: Direct toxic effect of iodide in excess on iodine-deficient thyroid glands: Epithelial necrosis and inflammation associated with lipofuscin accumulation. Exp Mol Pathol 44: 259-271, 1986.

10. Contempre B, Denef JF, Dumont JEMM and Many MC: Selenium deficiency aggravates the necrotizing effects of a high iodide dose in iodine deficient rats. Endocrinology 132: 1866-1868, 1993.

11. Contempre B, Le Moine O, Dumont JE, Denef JF and Many MC: Selenium deficiency and thyroid fibrosis. A key role for macrophages and transforming growth factor beta (TGF-beta). Mol Cell Endocrinol 124: 7-15, 1996.

12. Chiu-Ugalde J, Wirth EK, Klein MO, Sapin R, Fradejas-Villar N, Renko K, Schomburg L, Köhrle J and Schweizer U: Thyroid function is maintained despite increased oxidative stress in mice lacking selenoprotein biosynthesis in thyroid epithelial cells. Antioxid Redox Signal 17: 902-913, 2012.

13. Kolypetri P, Noel NA, Carayanniotis KA and Carayanniotis G: Iodine content of thyroglobulin in Nod. $\mathrm{H} 2^{\mathrm{h} 4}$ mice developing iodine-accelerated autoimmune thyroiditis. Hormones (Athens) 9: 151-160, 2010.

14. Arata N, Ando T, Unger P and Davies TF: By-stander activation in autoimmune thyroiditis: Studies on experimental autoimmune thyroiditis in the $\mathrm{GFP}^{+}$fluorescent mouse. Clin Immunol 121: 108-117, 2006.

15. Rasooly L, Burek CL and Rose NR: Iodine-induced autoimmune thyroiditis in NOD-H-2 ${ }^{\text {h4 }}$ mice. Clin Immunol Immunopathol 81: 287-292, 1996.

16. Čiháková D, Sharma RB, Fairweather D, Afanasyeva M and Rose NR: Animal models for autoimmune myocarditis and autoimmune thyroiditis. In: Autoimmunity: Methods and Protocols. Perl A (ed). Humana Press, Totowa, NJ, pp175-193, 2004. 
17. Pitsiavas V, Smerdely P, Li M and Boyages SC: Amiodarone induces a different pattern of ultrastructural change in the thyroid to iodine excess alone in both the $\mathrm{BB} / \mathrm{W}$ rat and the Wistar rat. Eur J Endocrinol 137: 89-98, 1997.

18. Gao J, Lin X, Liu X, Yang Q, Zhang Z, Jiang Q and Bian J: Effect of combined excess iodine and low-protein diet on thyroid hormones and ultrastructure in Wistar rats. Biol Trace Elem Res 155: 416-422, 2013

19. Bagchi N, Brown TR, Urdanivia E and Sundick RS: Induction of autoimmune thyroiditis in chickens by dietary iodine Science 230: 325-327, 1985.

20. Hassanin KM, Abd El-Kawi SH and Hashem KS: The prospective protective effect of selenium nanoparticles against chromium-induced oxidative and cellular damage in rat thyroid. Int J Nanomedicine 8: 1713-1720, 2013.

21. Roubaty C, Bedin C and Charreire J: Prevention of experimental autoimmune thyroiditis through the anti-idiotypic network. J Immunol 144: 2167 2172, 1990.

22. Cui SL, Yu J and Shoujun L: Iodine Intake Increases IP-10 Expression in the serum and thyroids of rats with experimental autoimmune thyroiditis. Int J Endocrinol 2014: 581069, 2014.

23. Risher J (ed): Toxicological Profile for Selenium (Update) DIANE Publishing, Darby, PA, 2011. https://books.google.com/ books?id=AEVdvRbs6xEC\&pgis=1.

24. Solcan C, Ciobanu C and Cuciureanu R: Dose-dependent subacute toxicity of sodium selenite in male Wistar rats. Jökull J 63: 57-69, 2013.

25. Effraimidis G and Wiersinga WM: Mechanisms in endocrinology: autoimmune thyroid disease: old and new players. Eur J Endocrinol 170: R241-R252, 2014.

26. Vanderpump MP, Tunbridge WM, French JM, Appleton D, Bates D, Clark F, Evans JG, Hasan DM, Rodgers H, Tunbridge F, et al: The incidence of thyroid disorders in the community: A twenty-year follow-up of the Whickham Survey. Clin Endocrinol (Oxf) 43: 55-68, 1995 .

27. Laurberg P, Pedersen KM, Hreidarsson A, Sigfusson N, Iversen E and Knudsen PR: Iodine intake and the pattern of thyroid disorders: A comparative epidemiological study of thyroid abnormalities in the elderly in Iceland and in Jutland, Denmark. J Clin Endocrinol Metab 83: 765-769, 1998.

28. Fountoulakis S, Philippou G and Tsatsoulis A: The role of iodine in the evolution of thyroid disease in Greece: From endemic goiter to thyroid autoimmunity. Hormones (Athens) 6: 25-35, 2007.

29. NielsenE,GreveK,Larsen JC,MeyerO,KrogholmK andHansen M: Iodine, Inorganic and Soluble Salts. The Danish Environmental Protection Agency, Copenhagen K, Denmark, 2014. https://www2. mst.dk/Udgiv/publications/2014/01/978-87-93026-87-2.pdf.

30. Yanagisawa M, Hara Y, Satoh K, Tanikawa T, Sakatsume Y, Katayama S, Kawazu S, Ishii J and Komeda K: Spontaneous Autoimmune Bio Breeding/Worcester Thyroiditis in (BB/W). Rat 33: 851-861, 1986.
31. Li M, Eastman CJ and Boyages SC: Iodine induced lymphocytic thyroiditis in the $\mathrm{BB} / \mathrm{W}$ rat: Early and late immune phenomena. Autoimmunity 14: 181-187, 1993.

32. Barin JG, Talor MV, Sharma RB, Rose NR and Burek CL: Iodination of murine thyroglobulin enhances autoimmune reactivity in the NOD.H2 mouse. Clin Exp Immunol 142: 251-259, 2005.

33. Zhu YP, Bilous $M$ and Boyages SC: Excess iodine induces the expression of thyroid solid cell nests in lymphocytic thyroiditis-prone BB/W rats. Autoimmunity 20: 201-206, 1995.

34. Lupachik SV, Nadol'nik LI, Netsetskaya ZV and Vinogradov VV: Effect of long-term injection of high doses of potassium iodide on iodine metabolism in rat thyroid gland. Biochem Suppl Ser B: Biomed Chem 1: 53-57, 2007.

35. Ruwhof $\mathrm{C}$ and Drexhage HA: Iodine and thyroid autoimmune disease in animal models. Thyroid 11: 427-436, 2001.

36. Amara IB, Bouaziz H, Guermazi F and Zeghal N: Effect of selenium on hypothyroidism induced by methimazole (MMI) in lactating rats and their pups. Acta Biol Hung 61: 145-157, 2010.

37. Jacobson DL, Gange SJ, Rose NR and Graham NMH: Epidemiology and estimated population burden of selected autoimmune diseases in the United States. Clin Immunol Immunopathol 84: 223-243, 1997.

38. Xiang Y, Jin Q, Li L, Yang Y, Zhang H, Liu M, Fan C, Li J, Shan Z and Teng W: Physiological low-dose oestrogen promotes the development of experimental autoimmune thyroiditis through the up-regulation of Th1/Th17 responses. J Reprod Immunol 126: 23-31, 2018.

39. Kincade PW, Medina KL, Smithson G and Scott DC: Pregnancy: A clue to normal regulation of B lymphopoiesis. Immunol Today 15: 539-544, 1994

40. Yin X, Latif R, Tomer Y and Davies TF: Thyroid epigenetics: $\mathrm{X}$ chromosome inactivation in patients with autoimmune thyroid disease. Ann N Y Acad Sci 1110: 193-200, 2007.

41. Chailurkit LO, Aekplakorn W and Ongphiphadhanakul B: The relationship between circulating estradiol and thyroid autoimmunity in males. Eur J Endocrinol 170: 63-67, 2013.

42. Chen Y, Chen Y, Xia F, Wang N, Chen C, Nie X, Li Q, Han B, Zhai H, Jiang B, et al: A higher ratio of estradiol to testosterone is associated with autoimmune thyroid disease in males. Thyroid 27: 960-966, 2017

43. Falgarone G, Heshmati HM, Cohen R and Reach G: Mechanisms in endocrinology. Role of emotional stress in the pathophysiology of Graves' disease. Eur J Endocrinol 168: R13-R18, 2012.

This work is licensed under a Creative Commons Attribution-NonCommercial-NoDerivatives 4.0 International (CC BY-NC-ND 4.0) License. 